\title{
Differential regulation of amphetamine-induced serotonergic and dopaminergic efflux by syntaxin $1 \mathrm{~A}$
}

\author{
Therese Montgomery, Sonja Sucic, Thomas Steinkellner, Michael Freissmuth, Harald Sitte* \\ From 17th Scientific Symposium of the Austrian Pharmacological Society (APHAR). Joint meeting with the \\ Hungarian Society of Experimental and Clinical Pharmacology (MFT) \\ Innsbruck, Austria. 29-30 September 2011
}

\section{Background}

The plasma membrane serotonin transporter (SERT) is a key regulator of synaptic serontonergic neurotransmission and is a major target of both antidepressents and psychostimulant drugs of abuse. The pre-synaptic soluble $\mathrm{N}$-ethylmaleimide-sensitive factor attachment protein receptor (SNARE) protein syntaxin 1A has been reported to modulate the intrinsic activity of multiple monoamine neurotransmitter transporters both in vitro and ex vivo. However, in contrast to the dopamine transporter (DAT) little is know of its effect on SERT-dependent amphetamine-mediated efflux in neuronal cells. Thus, the purpose of this study was to examine the specific effects of syntaxin $1 \mathrm{~A}$ on both SERT function and regulation by common drugs of abuse.

\section{Methods}

Murine catecholaminergic cells (CAD cells) were transiently transfected with either DAT or SERT in the presence and absence of syntaxin 1A. Transporter function was assessed by $\left[{ }^{3} \mathrm{H}\right] \mathrm{MPP}+$ and $\left[{ }^{3} \mathrm{H}\right] 5-\mathrm{HT}$ uptake, respectively. The cells were pre-loaded with $\left[{ }^{3} \mathrm{H}\right] \mathrm{MPP}+$ and superfused with amphetamines in order to determine the effect of syntaxin $1 \mathrm{~A}$ co-expression on amphetamine-mediated transporter-dependent efflux. Mutagenesis was performed using the QuikChange II site-directed mutagensis kit from Stratagene. Transporter and syntaxin $1 \mathrm{~A}$ co-localisation was confirmed using confocal microscopy.

\footnotetext{
* Correspondence: harald.sitte@meduniwien.ac.at Institute of Pharmacology, Center of Physiology and Pharmacology, Medical University of Vienna, 1090 Vienna, Austria
}

\section{Results}

The co-expression of SERT and syntaxin 1A led to a significant reduction in the $\mathrm{V}_{\max }$, but not the $\mathrm{K}_{\mathrm{m}}$, for $\left[{ }^{3} \mathrm{H}\right] 5$ HT uptake. Similarly, syntaxin 1A co-expression greatly reduced parachloroamphetamine-induced SERT-dependent efflux. Neither the pharmacological inhibition of CaMKII, nor the mutation of a CaMKII-binding motif in the $\mathrm{N}$-terminal tail of SERT had any effect on the downregulation of SERT activity by syntaxin $1 \mathrm{~A}$ in neuronal cell lines. In contrast to SERT, the co-expression of syntaxin $1 \mathrm{~A}$ and DAT had no effect on $\left[{ }^{3} \mathrm{H}\right] \mathrm{MPP}+$ uptake via DAT. Moreover, D-amphetamine-induced efflux via DAT was increased by the co-expression of syntaxin $1 \mathrm{~A}$.

\section{Conclusions}

In contrast to DAT, syntaxin $1 \mathrm{~A}$ is a negative regulator of amphetamine-induced SERT-mediated efflux, an effect which occurs independently of CaMKII activation. The significance of this differential regulation is currently being investigated using endogenous expression systems.

\section{Acknowledgements \\ This work was supported by a Marie Curie fellowship in conjunction with the Irish Health Research Board.}

Published: 5 September 2011

doi:10.1186/1471-2210-11-S2-A38

Cite this article as: Montgomery et al:: Differential regulation of amphetamine-induced serotonergic and dopaminergic efflux by syntaxin 1A. BMC Pharmacology 2011 11(Suppl 2):A38.

\section{Biomed Central}

(c) 2011 Montgomery et al; licensee BioMed Central Ltd. This is an open access article distributed under the terms of the Creative Commons Attribution License (http://creativecommons.org/licenses/by/2.0), which permits unrestricted use, distribution, and reproduction in any medium, provided the original work is properly cited. 